\title{
Inpatient and outpatient health care utilization and expenditures among older adults aged 50 years and above in India
}

\author{
Ankit Anand ${ }^{1 *}$ \\ ${ }^{1}$ Population Research Centre, Institute for Social and Economic Change, Bangaluru, India
}

Received:

08 March 2016

Revised:

11 June 2016

Accepted:

07 July 2016

\section{*Correspondence: ankit.anand189@gmail.com Research Scholar Population Research Centre, Institute for Social and Economic Change, Bangalore, India}

\begin{abstract}
Background: Social and economic inequality in utilization of health care services, as well as high out of pocket expenditures are prevalent in overall Indian population. The situation among older adults will be much more critical as they require long-term health care services. The objective of this study is to assess the utilization of outpatient and inpatient care among older adults and incurred out of pocket health expenditure. It also tried to explore the association between socioeconomic factors on receiving health care services and out of pocket health expenditure among older adults in India.
\end{abstract}

Data source: The data from the Study on Global Ageing and Adult Health (SAGE) Wave 1 was used, which was conducted in 2007-08 in India. Respondents aged 50 and above are taken as older adult population. The final sample size was 7150 respondents aged 50 years and above.

Results: The percentage of older adults aged 50 years and above receiving outpatient and inpatient health care service were $87.5 \%$ and $14.6 \%$ respectively. The use of private health facilities was high compared to government health facility. High utilization of outpatient among women and high use of inpatient care among men were found, which was insignificant after adjusting for other variables. Socioeconomic characteristics also play an important role in access to health care among older adults. Place of residence, marital status, caste, education and presence of morbidity were related to the utilization of health care services. Place of residence, education and wealth quintile were also significantly associated with health expenditures.

Conclusion: Requirement of long-term health care among older adult population may result in increasing burden of health care expenditures. Socioeconomic characteristics also play an important role in access to health care among older adults. Developing quality and affordable health care services for older adults to ensure equity in accessibility and affordablility will be a major task for the public health system in India.

Keywords: health care utilization, out of pocket expenditure, older adults, India

Suggested citation: Anand A. Inpatient and outpatient health care utilization and expenditures among older adults aged 50 years and above in India. Health Prospect. 2016;15(2):11-19.

Tweetable abstract: Older adults reported dependence on private health care, which led to high out of pocket expenditures among them.

\section{Introduction}

Population ageing is an upcoming phenomenon in India. India will be a major contributor of the older adult population in the future (1). The proportion of older adults aged 60 and above in India is $8.6 \%$ and which is projected to be more than $12 \%$ in 2026 and $20.2 \%$ by 2050 (1-3). There are huge implications for public health on population ageing in India. As we know health needs of older adults are quite different. Non-communicable diseases are more common in older ages and increase in the proportion of older adults will enhance the burden of non-communicable disease (4). Given away the inadequate public health care system and the increased need for health care among older population, the future ageing of the population in India poses a serious concern in providing access to specialized health care and financing these health care services (5).

Roy and Chaudhuri 2008 found that older men have more likely to use emergency services involving hospitalization, while older women use more primary and community health care services in India (6). Another study on Asian countries found significant differences in utilization of health care services by age, sex and education (7). Studies in India had also found that poor and rural population had less access to health care services and are vulnerable to financial risk posed by episodes of chronic illness (8-9). The private sector is the biggest source of providing health care services in India. The inability of public health providers to provide quality health care services and increasing dependence on private health care in India led to the high burden 
of health care expenditures (9). The inadequate public health infrastructure in India left no choice to rely on the private health system, which involves increased expenditure on health (10). Expenditures on both inpatient and outpatient health care are higher in private facilities as compared to public facilities. There are few studies in India showing that a high percent of expenditure on health is out of pocket and contributed in enhancing poverty (8-10). Socio-economic inequality in access tohealth care as well as high out of pocket expenditures was found in overall Indian population (11).The situation among older adults will be much more severe as they need more specialized health care services compared to other age groups.

There are not many studies in India which have assessed the burden of out of pocket health care expenditures in older adults.It is imperative to understand the health needs of the older generation and develop equality in access to the health care system among ever increasing ageing population of India. Hence, the objective of this study was to assess the utilization of outpatient and inpatient care among older adults and analyze the out of pocket health expenditure incurred during the recent outpatient and inpatient care among older adults. This paper has explored the association between socioeconomic factors on receiving health care services and out of pocket health expenditure among older adults in India.

\section{Data source}

The data from the Study on Global Ageing and Adult Health (SAGE) Wave 1 was used, which was conducted in 2007-08 in India. A multistage, stratified, random cluster sampling design was used. In India data was collected from six states Assam, Karnataka, Maharashtra, Rajasthan, Uttar Pradesh and West Bengal. The same primary sampling units (PSUs) and households covered in the World Health Survey (WHS-2003) comprised the baseline sample for SAGE Wave 1 India in 200708. The primary sampling units were stratified by region and location (urban/rural) and, within each stratum, enumeration areas were selected (12). The details are also given on SAGE website (http://www.who.int/healthinfo/systems/sage). It was a cross-sectional household survey which collected information on adults aged 18 years and above. Face to face interviews were done to collect information. India is recently experiencing increasing older adult population, with rising burden of noncommunicable diseases. To provide insight on the recent epidemiological changes and rising burden of health care, responded aged 50 and above were taken as older adult population; similar to WHO-SAGE report (13). The final sample size was 7150 respondents aged 50 years and above. The distribution of sample by each state is given in Table 1 .

\section{Dependent variables}

Information regarding the inpatient and outpatient visits wascollected. The reference period for inpatient care and outpatient care was 3 and 1 year, respectively. The reference period was taken as 3 and 1 year to reduce recall biases and focusing on the more recent scenario. The questions are as follows:

- In the last 3 years, have you ever stayed overnight in a hospital or long-term care facility?

- $\quad$ Over the last 12 months, did you receive any health care not including an overnight stay in hospital or long-term care facility?

The questions were asked about the out of pocket health care expenditure to the respondent who received either inpatient or outpatient care. The total amount in rupees was noted down. The questions are as follows:

- Thinking about your last [inpatient/hospital] stay, how much did you or your family/household members pay out of- pocket?

- Thinking about your last visit [outpatient], how much did you or your household pay?

\section{Independent variables}

The utilization of health care can be determined by multiple factors, such as demographic (age, sex, residence, and marital status), socioeconomic characteristics (caste, religion, education, employment and wealth), and health condition (chronic morbidity). Wealth quintiles were derived from the ownership of durable goods, household dwelling characteristics and household amenities. The total 20 variables used to generate wealth index. The principal component method was used to generate wealth scores, which was divided into 5 categories. Working status was divided into three categories; never worked (who never worked in their lifetime), currently working and past worker (who worked in the past but not currently working). The morbidity related information for angina, arthritis, asthma, cataract, chronic lung diseases, diabetes, depression, and stroke was collected. The presence of more than two morbidities was categorized as multiple morbidity. The presence of only one morbidity was categorized as single morbidity. The respondent reported having any health insurance was recoded as having health insurance.

\section{Statistical analysis}

Bivariate analysis was performed to see the utilization of health care and to calculate mean health expenditure on outpatient and inpatient health care services by different socio-economic characteristics. Sample estimates have been weighted for agesex distribution using the census of India 2001. Outliers in

Table 1: Sample distribution of older adults (SAGE-2007-08) by states and place of residence

\begin{tabular}{llll}
\hline State & Urban & Rural & Total \\
\hline Assam & 140 & 578 & 718 \\
Karnataka & 336 & 697 & 1033 \\
Maharashtra & 522 & 724 & 1246 \\
Rajasthan & 274 & 1193 & 1467 \\
Uttar Pradesh & 222 & 1204 & 1426 \\
West Bengal & 367 & 893 & 1260 \\
Total & $\mathbf{1 8 6 1}$ & $\mathbf{5 2 8 9}$ & $\mathbf{7 1 5 0}$ \\
\hline
\end{tabular}


Table 2: Odds ratio of receiving health care services by selected socioeconomic characteristics among older adults aged 50 years and above Out-Patient $^{@} \quad$ In-Patient ${ }^{@}$ $(\mathrm{N}=5768)$

$(\mathrm{N}=5732)$

Age group

50-59\#

60-69

$1.02(0.85-1.21) \quad 0.99(0.82-1.19)$

70 and above

$1.22(0.97-1.54)$

$1.13(0.91-1.41)$

Gender

Male\#

Female

$1.22(0.99-1.50)$

0.95(0.77-1.17)

Place of residence

Urban\#

Rural

$0.87(0.72-1.05) \quad 1.10(0.91-1.33)$

Marital status

Never married\#

Currently Married

$1.78(0.93-3.37)$

2.73(0.84-8.79)

Widowed/Separated

$1.88(0.99-3.64)^{*}$

2.34(0.71-7.73)

\section{Religion}

Muslim\#

Hindu

Others

Caste

SC/ST\#

Others

\section{Education}

No education\#

Less than Primary

$0.77(0.60-0.98)^{*}$

0.95(0.74-1.23)

Primary Completed

$0.99(0.77-1.26)$

Secondary Completed $\quad 0.86(0.65-1.14)$

Higher secondary and $\quad 0.78(0.59-1.02)$ 0.95(0.75-1.20) 0.83(0.61-1.11) 0.84(0.63-1.11)

above

Wealth quintile

Lowest\#

Second

Third

Fourth

Highest

Working status

Never Worked\#

Currently Working

Past Worker

Morbidity

No Morbidity\#

Single Morbidity

Multiple Morbidities

$1.77(1.46-2.13)^{\star *} \quad 1.79(1.49-2.15)^{\star *}$ $2.06(1.63-2.61)^{* *} \quad 3.25(2.68-3.93)^{* *}$

\section{Health insurance}

No\#

Yes

Log likelihood

$1.47(0.99-2.20)^{*}$

$1.70(1.25-3.21)^{\star *}$

Pseudo R square $-2305.6457$

$-2231.0065$

0.0238

0.0460

@ Reference period for outpatient was last 1 year and for inpatient was last 3 years; \# Reference category, ${ }^{*} \mathrm{P}<0.05$, ${ }^{*} \mathrm{P}<0.01$

Table 3: Mean Out of Pocket Health Expenditure (in US dollar) during last recent visit by selected socio-economic characteristics among older adults aged 50 years and above

\begin{tabular}{|c|c|c|}
\hline & $\begin{array}{l}\text { Out-Patient }^{@} \\
\text { (lower-upper) }^{-}\end{array}$ & $\begin{array}{l}\text { In-Patient }^{@} \\
\text { (lower-upper) }\end{array}$ \\
\hline Overall average & $10.6(9.2-12.1)$ & $192.1(140.3-243.9)$ \\
\hline \multicolumn{3}{|l|}{ Age group } \\
\hline $50-59$ & $10.0(7.9-12.1)$ & $190.3(117.1-263.5)$ \\
\hline $60-69$ & $11.0(9.2-12.8)$ & $213.1(105.4-320.7)$ \\
\hline 70 and above & $11.5(8.3-14.7)$ & $169.3(114.8-223.9)$ \\
\hline \multicolumn{3}{|l|}{ Gender } \\
\hline Male & $12.3(9.9-14.6)$ & $242.6(151.1-334.0)$ \\
\hline Female & $9.0(7.7-10.2)$ & $136.7(104.8-168.7)$ \\
\hline \multicolumn{3}{|l|}{ Place of residence } \\
\hline Urban & $11.6(8.1-15.2)$ & $240.3(86.3-394.4)$ \\
\hline Rural & $10.2(8.7-11.6)$ & $170.6(131.0-210.2)$ \\
\hline \multicolumn{3}{|l|}{ Marital status } \\
\hline Never married & $8.7(4.5-12.9)$ & - \\
\hline Currently Married & $11.3(9.6-13.0)$ & $205.9(145.0-266.8)$ \\
\hline Widowed/Separated & $8.5(7.0-10.0)$ & $107.7(83.4-132.0)$ \\
\hline \multicolumn{3}{|l|}{ Religion } \\
\hline Muslim & $10.5(6.9-14.1)$ & $124.3(78.8-169.9)$ \\
\hline Hindu & $10.7(9.2-12.3)$ & $205.9(142.7-269.1)$ \\
\hline Others & $7.7(4.9-10.5)$ & $176.7(68.2-285.3)$ \\
\hline \multicolumn{3}{|l|}{ Caste } \\
\hline SC/ST & $7.0(5.7-8.2)$ & $112.5(64.7-160.1)$ \\
\hline Others & $11.7(9.9-13.4)$ & $208.1(146.1-270.1)$ \\
\hline
\end{tabular}

\section{Education}

No education

$8.6(7.4-9.8)$

$131.5(97.8-165.2)$

Less than Primary

$8.2(6.3-10.0)$

$120.2(59.2-181.3)$

Primary Completed

$11.2(6.3-16.2)$

$168.5(104.3-232.7)$

Secondary Completed

$12.9(7.1-18.7)$

$449.4(68.3-830.5)$

Higher secondary and

$17.8(12.9-22.7)$

370.9 (154.0-587.9)

above

Wealth quintile

Lowest

$6.4(5.1-7.7)$

$109.3(29.6-189.1)$

Second

Third

Fourth

$6.8(5.4-8.1)$

$98.0(70.2-125.8)$

$9.6(7.3-11.9)$

$167.8(95.1-240.5)$

$11.6(7.7-15.5)$

$163.0(113.5-212.5)$

Highest

17 (13.5-20.5)

352.2 (185.1-519.3)

Working status

Never Worked

Currently Working

$9.5(7.9-11.2)$

$157.6(107.5-207.7)$

$9.5(7.2-11.7)$

147.8 (93.9-201.8)

Past Worker

$13.2(10.4-16)$

$254.7(135.6-373.7)$

Morbidity

No Morbidity

7.8 (6.6-9.0)

139.6 (90.6-188.6)

Single Morbidity

$11.1(9.0-13.2)$

$161.9(108.1-215.7)$

Multiple Morbidities

$18.2(12.5-24.0)$

$279.6(149.6-409.7)$

@ Reference period for outpatient was last 1 year and for inpatient was last 3 years 
Table 3: Mean Out of Pocket Health Expenditure (in US dollar) during last recent visit by selected socio-economic characteristics among older adults aged 50 years and above contd...

$\begin{array}{ll}\text { Out-Patient }^{@} & \begin{array}{l}\text { In-Patient }^{@} \\ \text { (lower-upper) }\end{array}\end{array}$

Type of facility

$\begin{array}{lll}\text { Public } & 8.5(7.0-10.0) & 130.8(62.6-198.9) \\ \text { Private } & 13.1(11-15.2) & 238.3(165.4-311.2) \\ \text { Others } & 3.5(2.7-4.3) & 35.3(5.8-64.9) \\ \text { Health insurance } & & \\ \text { No\# } & 10.4(8.9-11.8) & 193.4(139.1-247.6) \\ \text { Yes } & 16.5(9.7-23.2) & 180.8(82.1-270.5)\end{array}$

@ Reference period for outpatient was last 1 year and for inpatient was last 3 years; \# Reference category, ${ }^{\star} \mathrm{P}<0.05$, ${ }^{* *} \mathrm{P}<0.01$

health expenditure data were found by plotting the data. Extreme values in health expenditure were removed from the analysis as they were found to influence the statistics significantly. Stepwise logistic regression was done to know the determinants for utilization of health care services among older adults. The odds ratio of receiving inpatient and outpatient was calculated. The information on health expenditures was collected in rupees (currency of India). For better understanding the mean of health expenditure was converted into dollars, by applying the average conversion rate of rupees to dollars in 2007 (http://usd.lookly.com/INR/c1/). Multiple linear regression analysis was done on the log of health expenditure to get the important factors responsible for increased health expenditure. Linear regression performed for cases which have reported out of pocket expenditure. The log transformation of expenditure and the model have met the normality and heteroscedasticity assumptions of linear regression. Possible interaction between independent variables were also explored. Stata-12 was used to perform these analyses.

\section{Results}

Utilization of inpatient and outpatient health care among older adults

As shown in Figure 1, 87.5\% of older adults had utilized outpatient health care in last 12 months. $14.6 \%$ of older adults have received inpatient health care services during last 3 years. Utilization of outpatient and inpatient health care was higher for older age groups. Older female adults had higher utilization of outpatient care but lower utilization of inpatient care, compared to older male adults. Among adults who received outpatient care, $61.8 \%$ of them received in private health care facility, and $22.1 \%$ received in government health care facility (as shown in Figure 2). Similarly, among older adults who received inpatient care, $58.4 \%$ of them received in private health care facility and $36.7 \%$ of them received in government health care facility. Utili-
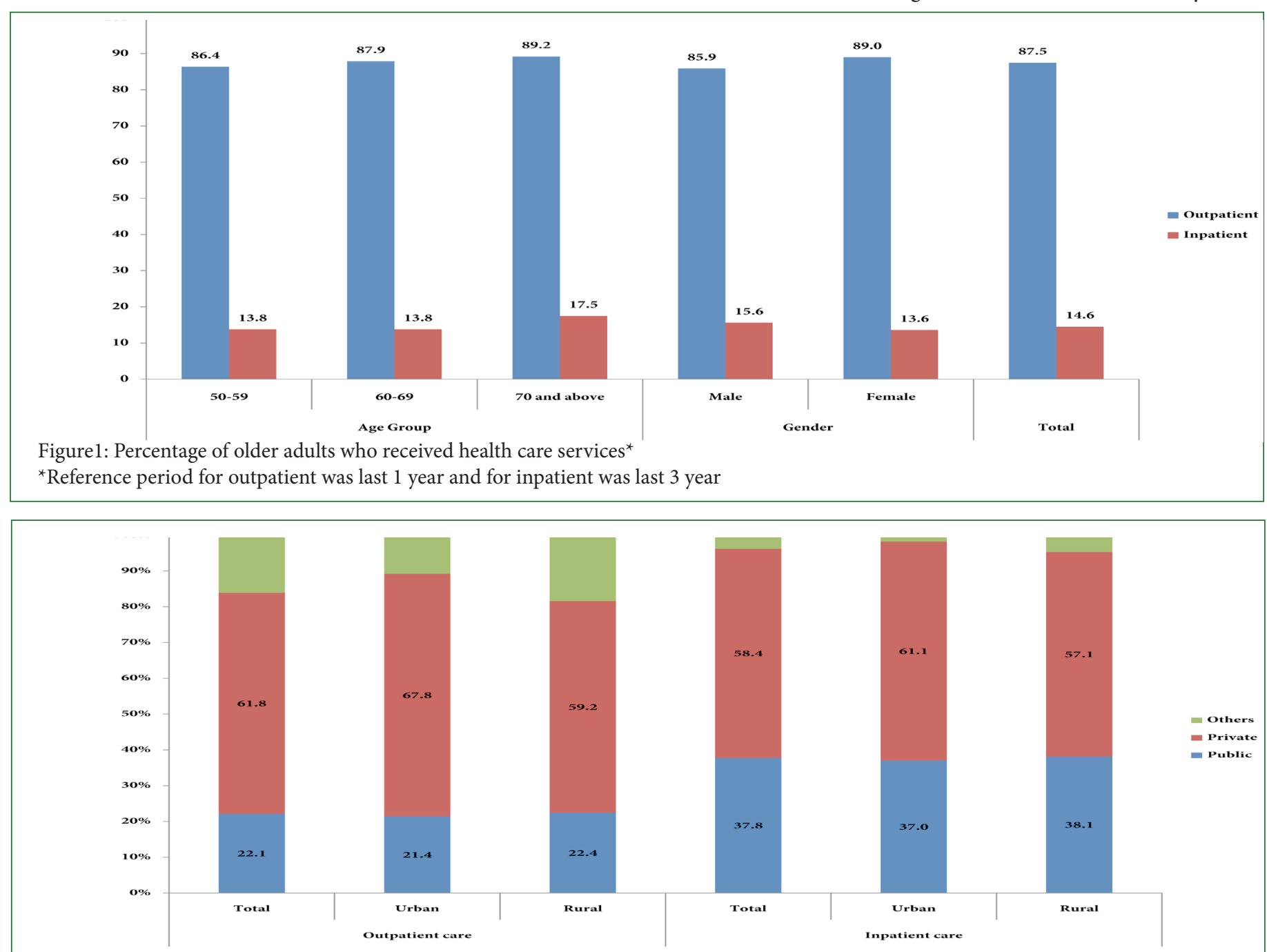

Figure2: Percent distribution of older adults who received health care services by type of facility and place of resident*

${ }^{*}$ Reference period for outpatient was last 1 year and for inpatient was last 3 year 


\begin{tabular}{|c|c|c|c|c|c|c|}
\hline \multirow{3}{*}{ Background characteristics } & \multirow{3}{*}{ B coefficient } & \multirow{2}{*}{\multicolumn{2}{|c|}{$\begin{array}{l}\text { Outpatient expenditure } \\
\qquad 95 \% \mathrm{CI}\end{array}$}} & \multicolumn{3}{|c|}{ Inpatient expenditure } \\
\hline & & & & \multirow[t]{2}{*}{ B coefficient } & \multicolumn{2}{|c|}{ 95\% CI } \\
\hline & & Lower & Upper & & Lower & Upper \\
\hline \multicolumn{7}{|l|}{ Age group } \\
\hline \multicolumn{7}{|l|}{ 50-59\# } \\
\hline $60-69$ & 0.055 & -0.036 & 0.146 & -0.202 & -0.491 & 0.086 \\
\hline 70 and above & 0.025 & -0.088 & 0.138 & -0.097 & -0.439 & 0.245 \\
\hline \multicolumn{7}{|l|}{ Gender } \\
\hline \multicolumn{7}{|l|}{ Male\# } \\
\hline Female & 0.028 & -0.077 & 0.134 & 0.174 & -0.163 & 0.510 \\
\hline \multicolumn{7}{|l|}{ Place of residence } \\
\hline \multicolumn{7}{|l|}{ Urban\# } \\
\hline Rural & $-0.112^{\star}$ & -0.207 & -0.021 & 0.040 & -0.253 & 0.333 \\
\hline \multicolumn{7}{|l|}{ Marital status } \\
\hline \multicolumn{7}{|l|}{ Never married\# } \\
\hline Currently Married & 0.133 & -0.295 & 0.565 & $2.953^{*}$ & 0.081 & 5.824 \\
\hline Widowed/Separated & 0.065 & -0.168 & 0.030 & -0.105 & -0.423 & 0.213 \\
\hline \multicolumn{7}{|l|}{ Religion } \\
\hline \multicolumn{7}{|l|}{ Muslim\# } \\
\hline Hindu & 0.027 & -0.094 & 0.149 & -0.103 & -0.519 & 0.312 \\
\hline Others & 0.069 & -0.182 & 0.312 & 0.135 & -0.560 & 0.830 \\
\hline \multicolumn{7}{|l|}{ Caste } \\
\hline \multicolumn{7}{|l|}{ SC/ST\# } \\
\hline Others & 0.068 & -0.033 & 0.170 & 0.102 & -0.237 & 0.449 \\
\hline \multicolumn{7}{|l|}{ Education } \\
\hline \multicolumn{7}{|l|}{ No education\# } \\
\hline Less than Primary & -0.102 & -0.233 & 0.030 & 0.175 & -0.233 & 0.583 \\
\hline Primary Completed & -0.090 & -0.212 & 0.032 & -0.121 & -0.497 & 0.255 \\
\hline Secondary Completed & -0.090 & -0.239 & 0.058 & $0.560^{*}$ & 0.061 & 1.060 \\
\hline Higher secondary and above & 0.111 & -0.033 & 0.255 & $0.636^{\star *}$ & 0.166 & 1.106 \\
\hline \multicolumn{7}{|l|}{ Wealth quintile } \\
\hline \multicolumn{7}{|l|}{ Lowest\# } \\
\hline Second & $0.135^{\star}$ & 0.003 & 0.268 & 0.126 & -0.294 & 0.547 \\
\hline Third & $0.298^{\star *}$ & 0.163 & 0.432 & 0.408 & -0.027 & 0.842 \\
\hline Fourth & $0.262^{* *}$ & 0.128 & 0.397 & $0.563^{* *}$ & 0.132 & 0.994 \\
\hline Highest & $0.555^{\star *}$ & 0.415 & 0.695 & $0.724^{\star \star}$ & 0.284 & 1.164 \\
\hline Working status & & & & & & \\
\hline Never Worked\# & & & & & & \\
\hline Currently Working & $-0.217^{\star \star}$ & -0.334 & -0.101 & -0.230 & -0.600 & 0.141 \\
\hline Past Worker & 0.105 & -0.006 & 0.217 & 0.217 & -0.118 & 0.551 \\
\hline Morbidity & & & & & & \\
\hline No Morbidity\# & & & & & & \\
\hline Single Morbidity & $0.212^{* *}$ & 0.121 & 0.303 & -0.162 & -0.463 & 0.138 \\
\hline Multiple Morbidities & $0.430^{\star *}$ & 0.340 & 0.555 & 0.147 & -0.156 & 0.449 \\
\hline Type of facility & & & & & & \\
\hline Public & & & & & & \\
\hline Private & $0.372^{\star *}$ & 0.276 & 0.468 & $0.762^{\star *}$ & 0.502 & 1.021 \\
\hline Others & $-0.724^{\star *}$ & -0.850 & -0.599 & -0.290 & -0.923 & 0.341 \\
\hline
\end{tabular}


Table 4: Results of multiple linear regression on log of out of pocket health expenditure contd...

\section{Outpatient expenditure}

Background characteristics

B coefficient

95\% CI

Lower Upper

Health insurance

No\#

Yes

0.129

$-0.508$

0.308

0.667

@ Reference period for outpatient was last 1 year and for inpatient was last 3 years

\# Reference category, ${ }^{*} \mathrm{P}<0.05,{ }^{*} \mathrm{P}<0.01$

zation of private health care facility was found to be higher than government health care facility.

\section{Determinants of utilization of inpatient and outpatient}

\section{health care among older adults}

Table 2 shows the odds of receiving outpatient and inpatient care among older adults. Older adults in rural areas $(\mathrm{OR}=0.87$, $\mathrm{p}>0.05$ ) had non-significantly lower odds of receiving outpatient care compared to older adults in urban areas. Currently widowed/separated older adults $(\mathrm{OR}=1.88, \mathrm{p}<0.05)$ had significantly higher odds of receiving outpatient as well as inpatient care compared to older adults who never get married. Others (other than Hindu/Muslims) in religion category had significantly higher odds of receiving inpatient care compare to Muslims $(\mathrm{OR}=2.24, \mathrm{p}<0.01)$. In caste categories, others (non scheduled caste/tribe) had significantly higher odds of receiving inpatient care compared to schedule caste/tribe $(\mathrm{OR}=1.34$, $\mathrm{p}>0.01)$. Increasing education and wealth quintile did not found to have much influence on receiving inpatient and outpatient care. Past worker $(\mathrm{OR}=1.31, \mathrm{p}<0.05)$ had significantly higher odds of receiving inpatient care compared to older adults who had never worked. Older adults with single morbidity had significantly higher odds of receiving inpatient $(\mathrm{OR}=1.79, \mathrm{p}<0.01)$ as well as outpatient care $\mathrm{OR}=1.77, \mathrm{p}<0.01$ ) compared to adults who did not have any chronic morbidity. Similarly, older adults with multiple morbidity had two-fold and three-fold utilization of outpatient $(\mathrm{OR}=2.06, \mathrm{p}<0.01)$ and inpatient $(\mathrm{OR}=3.25$, $\mathrm{p}<0.05)$ care respectively, compared to older adults with no chronic morbidity. Having health insurance was also related to increased utilization of outpatient $(\mathrm{OR}=1.47, \mathrm{p}<0.05)$ and inpatient care $(\mathrm{OR}=1.70, \mathrm{p}<0.01)$.

Out of pocket health expenditure for recent outpatient and inpatient health care visit among older adults

Mean out of pocket health expenditure for recent outpatient care in last 24 months among older adults was \$10.6 (Rs. 437.7) (as shown in Table 3 and Appendix 1). Mean out of pocket health expenditure for recent inpatient care in last 3 years among older adults was \$192.1 (Rs. 7925.7). Older adults aged 70 and above had the highest mean out of pocket health expenditure for recent outpatient care. The age group 60-69 years had the highest mean out of pocket health expenditure for recent inpatient care. Older male adults had higher mean out of pocket health expenditure for both inpatient and outpatient care compared to older female adults. Older adults residing in urban areas had higher mean out of pocket health expenditure for both inpatient and outpatient care compared to older adults residing in rural areas. Currently married older adults had the highest mean out of pocket health expenditure for inpatient and outpatient care in the marital status category. In the caste categories, the scheduled caste/tribe had the lowest mean out of pocket health expenditure for inpatient and outpatient care. The highest category in education and wealth categories had the highest mean out of pocket health expenditure for inpatient and outpatient care. Older adults who had worked in the past had higher mean out of pocket health expenditure for inpatient and outpatient care compared to older adults who had never worked. Older adults with single and multiple morbidities had higher mean out of pocket health expenditure compared to older adults who had no chronic morbidity. Older adults who received health care in private health care services, the average out of pocket expenditure were almost double to those who received in public health care service. Older adults reported having health insurance had higher out of pocket expenditure for outpatient care, but lower for inpatient care compared to older adults without health insurance.

Factors influencing health expenditures among older adults Table 3 showed the result of multiple linear regression on the log of out of pocket health expenditure. Currently married older adults had higher out of pocket health expenditure for inpatient care compared to adults who never got married. Rural areas had significantly lower out of pocket health expenditure on outpatient care compared to urban areas. Having secondary and higher education among older adults significantly increased the out of pocket health expenditure on inpatient care. Increasing wealth quintile categories also lead to increasing out of pocket health expenditure for both inpatient and outpatient care. Having multiple morbidities among older adults lead to significantly increased health expenditure for both inpatient and outpatient care. The out of pocket expenditure on health was significantly higher in private health care services.

\section{Discussion}

Relatively higher percentage of the older adult population was using health care facilities in our study compared to the previous studies in India (14-15). In our study, respondents were asked whether they went to seek medical care or not (not for any specific disease or condition). The care received may or may not be geriatrics. It reflects the demand of health care services among older adults. As shown in the various literature, the need of long-term health care is very common among older adults (16-18). Hence, the need and importance of developing geriat- 
rics care cannot be ignored. Most importantly private sector is the biggest provider of health care services among older adults in India as well as in many Asian countries such as China, Vietnam, Nepal and Bangladesh $(7,19-20)$. The dependence on private health care in these countries causes a high financial burden on population groups such as older adults. Studies comparing multiple Asian countries found that India has one of the highest shares of out of pocket expenditure to total health expenditure (20). A study using the National Sample Survey Organisation (NSSO) data had shown high use of private health facilities compared to public health services among 60 and above population in India (21). High utilization of private health care can lead to the increase in out of pocket health expenditure $(1,19)$. The out of pocket health expenditure for inpatient and outpatient care as estimated by NSSO is 214 rupees and 3543 rupees respectively for the overall population (10). Compared to our findings, the average cost of out of pocket expenditure is $10.6 \$$ (437 rupees) in outpatient and $192 \$$ (7925 rupees) in inpatient among older adults (Table 3 and Appendix 1). It may suggest that the cost of health care will be high in older ages. Studies in the past have shown the average share of expenditure on inpatient and outpatient care is lower, but expenditure on medicines is higher in the general population. The catastrophic health expenditure is known to push households below the poverty line (8-10). Socioeconomic vulnerabilities combined with the need for more health care and medicine among the older population are a concern for the public health system in India (8). This minimizes the health care accessibility of older adults belonging to vulnerable and poor section (such as a scheduled caste/tribe) of the population within the older adult population and enhances their chances of being in poor health with the financial burden (22). Socioeconomic conditions are important determinant of health care access in developing countries $(6,12,19-22)$. Utilization and expenditure on health care facility was significantly higher for older adults belonging to the other caste category compare to scheduled caste/tribe. Higher accumulation of wealth was also significantly associated with increased utilization and out of pocket expenditure on health care services. It can be inferred that the older adult in poverty ridden households will have less access to quality health care. The high out of pocket health expenditure may not allow the poor household to seek medical care when required (19). The estimates from the Ministry of Social Justice and Empowerment, Government of India had concluded that one-third of the population in the 60 plus age group is below poverty lines (23). The elimination of social and economic inequalities in access to healthcare among older persons had also been emphasized in the Madrid International Plan of Action on Ageing (24). The presence of chronic morbidity had also significantly associated with health care utilization and expenditures. Even studies from developed countries have shown increased use of health care among older adults who had single or multiple morbidities compared to older adults with no morbidity (25). Health insurance was related to increased utilization of health services. However, health insurance did not have significant influence on out of pocket health expenditure. The reason may be the health insurance in India is not strong enough to provide financial protection or there are also chances of reporting biases. It is interesting to find out that the factors which were responsible for increased utilization of health care, were also significantly associated with out of pocket health expenditure or vice-versa. The necessity to strengthen the public health care system for meeting the emerging needs of the older adult population are required (19-21). Increasing access to health care is very important in achieving better health among older adults. The protection to poor households from high financial risk by out of pocket health expenditures is also necessary for the public health system in India.

\section{Limitations of the study}

First, the information on health care utilization and expenditure were self-reported. It may also have recall bias, especially for expenditure data, which may affect the results. Another important limitation of the study is that it does not take account for the duration of stay in inpatient care. Expenditures questions were only asked for the recent outpatient and inpatient care, there could be more than one outpatient and inpatient health care visits in the reference period.

\section{Conclusions}

The older adult population in India will increase in near future. The public health system must adopt soon to meet the need for this section of the society. Use of private health care is very high in India. Increased dependency on private health facility will only lead towards high out of pocket health expenditure. The requirement of long-term health care among older adult population may result in increasing burden of health care expenditures. Socioeconomic characteristics also play an important role in access to health care among older adults. Developing quality and affordable health care services for older adults to ensure equity in accessibility will be a major task for the public health system in India. There is a requirement to improve the methodology for collecting detailed and quality data on the health expenditure in India.

\section{Competing interests}

There are no competing interests.

\section{Acknowledgements}

The author acknowledges the guidance and support provided by Dr. Dhananjay W. Bansod. The author is thankful to Ms. Annu Baranwal and Dr. Nobojit Roy and his Thursday research group for their comments and suggestions. The author is thankful to Dr. Judy H. Rustien for providing suggestions to improve the English writing of this manuscript.

\section{References}

1. United Nations, Population Ageing and Development, 2012:Datasheet. United Nations, Department of Economic and Social Affairs, Population Division 2012.

2. Registrar General and Census Commissioner, India, Population Projections for India and States, 2001-2026, Report of The Technical Group on Population Projections Constituted by the National Commission on Population. New Delhi 2006.

3. Registrar General of India, Census of India, Primary Census Abstract: Single Year Age Data: C13 Table. New Delhi: Registrar General and Census Commissioner of India, 2012. Available From: http://www.censusindia.gov. in/2011census/population_enumeration.aspx..

4. UNFPA - Population and Family Study Center, Population Ageing: challenges for policies and programmes in developed and developing countries. UNFPA and Population and Family Study Center, New York and Brussels 1999.

5. Ingle GK, Nath A. Geriatric health in India: Concerns and solutions. Indian journal of community medicine: official publication of Indian Association of Preventive \& Social Medicine. 2008; 33(4):214.

6. Roy K, Chaudhuri A. Influence of socioeconomic status, wealth and financial empowerment on gender differences in health and healthcare utilization in later life: evidence from India. Social science \& medicine. 2008; 
66(9):1951-62.

7. Xu K, Evans DB, Kawabata K, Zeramdini R, Klavus J, Murray CJ. Household catastrophic health expenditure: a multicountry analysis. The lancet. 2003; 362(9378):111-7

8. Balarajan Y, Selvaraj S, Subramanian SV. Health care and equity in India. The Lancet. 2011; 377(9764):505-15.

9. Garg CC, Karan AK. Reducing out-of-pocket expenditures to reduce poverty: a disaggregated analysis at rural-urban and state level in India. Health policy and planning. 2009; 24(2):116-28.

10. Selvaraj S, Karan AK. Deepening health insecurity in India: evidence from national sample surveys since 1980s. Economic and Political Weekly. 2009: 5560.

11. Kumar V. Health status and health care services among older persons in India. Journal of aging \& social policy. 2003; 15(2-3):67-83.

12. Kowal P, Chatterji S, Naidoo N, Biritwum R, Fan W, Ridaura RL, et al. Data resource profile: the World Health Organization Study on global AGEing and adult health (SAGE). International journal of epidemiology. 2012; 41(6):163949.

13. Arokiasamy P, Parasuraman S,Sekher TV, Lhungdim H. Study on global AGEing and adult health (SAGE) Wave 1. The India National Report. Geneva: World Health Organization. 2013.

14. Albanese E, Liu Z, Acosta D, Guerra M, Huang Y, Jacob KS, et al. Equity in the delivery of community healthcare to older people: findings from 10/66 Dementia Research Group cross-sectional surveys in Latin America, China, India and Nigeria. BMC health services research. 2011; 11(1):153.

15.Agrawal G, Arokiasamy P. Morbidity prevalence and health care utilization among older adults in India. Journal of Applied Gerontology. 2009.

16. Kespichayawattana J, Jitapunkul S. Health and health care system for older persons. Ageing international. 2008; 33(1-4):28-49.

17. Werblow A, Felder S, Zweifel P. Population ageing and health care expenditure: a school of'red herrings'? Health economics. 2007; 16(10):1109.

18. Yang Z, Norton EC, Stearns SC. Longevity and health care expenditures the real reasons older people spend more. The Journals of Gerontology Series B: Psychological Sciences and Social Sciences. 2003; 58(1):S2-10.

19. Yip W, Mahal A. The health care systems of China and India: performance and future challenges. Health Affairs. 2008; 27(4):921-32.

20. Van Doorslaer E, O’Donnell O, Rannan-Eliya RP, Somanathan A, Adhikari SR, Garg CC, et al. Effect of payments for health care on poverty estimates in 11 countries in Asia: an analysis of household survey data. The lancet. 2006;368(9544):1357-64.

21. Rajan SI. Population ageing and health in India. 2006, Mumbai.

22. Sudore RL, Mehta KM, Simonsick EM, Harris TB, Newman AB, Satterfield $\mathrm{S}$, et al. Limited literacy in older people and disparities in health and healthcare access. Journal of the American Geriatrics Society. 2006; 54(5):770-6.

23. Ministery of Social Justice and Empowerment.National policy on older person. New Delhi, 1999. Available From: http://socialjustice.nic.in/hindi/pdf/ npopcomplete.pdf.

24. United Nations. Madrid political declaration and international plan of action on ageing, 2002. International Social Science Journal 2006; 58: 633-665. doi: $10.1111 / j .1468-2451.2008 .00660 . x$

25. Koller D, Schön G, Schäfer I, Glaeske G, van den Bussche H, Hansen H. Multimorbidity and long-term care dependency-a five-year follow-up. BMC geriatrics. 2014; 14(1):70. 
Appendix 1: Mean out of pocket health expenditure (In Rupees) during last recent visit by selected socio-economic characteristics among older adults aged 50 years and above

\section{Outpatient Inpatient}

Age group

50-59\#

60-69

$412.0(325.7-498.3)$

$453.3(378.2-528.5)$

$473.1(341.8-604.5)$

70 and above

\section{Gender}

Male\#

$505.8(407.6-604.0)$

$370.3(318.2-422.3)$

Female

Place of residence

Urban\#

$480.4(335.7-625.1)$

Rural

Marital status

Never married\#

Currently Married

Widowed/Separated

\section{Religion}

Muslim\#

Hindu

Others

Caste

SC/ST\#

Others

\section{Education}

No education\#

Less than Primary

Primary Completed

Secondary Completed

Higher secondary and above

Wealth quintile

Lowest\#

Second

Third

Fourth

Highest

\section{Working status}

Never Worked\#

Currently Working

Past Worker

\section{Morbidity}

No Morbidity\#

Single Morbidity

Multiple Morbidities

\section{Health insurance}

No\#

Yes

Total
419.8 (359.2-480.4)

359.6 (187.2-531.9)

464.4 (394.5-534.3)

$349.6(287.1-412.1)$

434.3 (285.8-582.9)

442.5 (377.8-507.3)

318.6 (202.4-434.7)

$287.0(234.8-339.1)$

480.9 (408.3-553.4)

353.9 (305.5-402.2)

$337.0(259.7-414.3)$

$463.9(260.1-667.7)$

$532.5(292.8-772.2)$

$734.5(530.8-938.2)$

263.8 (211.1-316.4)

278.5 (222.4-334.6)

$395.2(299.8-490.6)$

$479.4(317.9-640.8)$

$701.3(556.2-846.3)$

393.2 (324.6-461.9)

390.9 (298.5-483.3)

543.0 (427.1-658.9)

322.8 (273.2-372.4)

458.2 (370.6-545.7)

752.5 (516.5-988.5)

426.5 (366.5-486.5)

678.2 (401.3-955.2)

437.7 (378.0-497.3)
7849.6 (4830.0-10869.3)

8789.9 (4349.3-13230.6)

6984.1 (4733.5-9234.6)

10005.3 (6234.5-13776.1)

5640.4 (4323.3-6957.6)

9913.4 (3558.5-16268.4)

7038.0 (5405.5-8670.6)

8493.9 (5980.3-11007.5)

4444.3 (3441.9-5446.8)

5128.9 (3248.5-7009.3)

8493.2 (5887.4-11099.0)

7289.5 (2811.3-11767.7)

4636.6 (2667.4-6605.7)

8573.9 (6018.7-11129.1)

$5425.2(4036.2-6814.1)$

4959.6 (2441.8-7477.3)

6950.8 (4301.0-9600.5)

18537.8 (2816.9-34258.6)

15301.6 (6352.1-24251.1)

4510.6 (1221.3-7800.0)

4043.8 (2896.4-5191.2)

6921.7 (3921.0-9922.4)

6722.1 (4680.3-8763.8)

14527.5 (7634.3-21420.8)

6500.3 (4434.3-8566.3)

6097.6 (3871.8-8323.4)

10505.3 (5595.1-15415.5)

5756.8 (3735.7-7777.9)

6678.6 (4460.9-8896.2)

11534.5 (6170.4-16898.7)

7966.8 (5730.6-10202.9)

7477.8 (3380.1-11515.4)

7925.6 (5788.5-10062.7)

${ }^{\star}$ Reference period for outpatient was last 1 year and for inpatient was last 3 year 